\title{
The Impact of Rhythm and Gender on Spelling Output of Iranian EFL Learners: A Cross-Sectional Study
}

\author{
Peyman Nouraey ${ }^{1}$ \\ Gulf College, Muscat, Oman \\ Amin Karimnia \\ Islamic Azad University, Fasa Branch, Iran
}

\section{Introduction}

Teaching English as a Foreign Language (henceforth TEFL) has always been referred to as a complicated process, containing different methods of teaching and learning in addition to some other concepts such as teacher or learner (Brown, 2000). In order to overcome the obstacles faced during these processes, several scholars have presented different meta-models as to what the basic concepts of TEFL relate to. Like any other theoretical construct, a meta-model is meant "to bring to the surface what is hidden" (Katan, 2004, p.127). These methods and models have had a great deal of contribution to different aspects of TEFL, including four main skills in learning a foreign language, namely listening, speaking, reading and writing. Thus, it is assumed that dealing with different hints and points which may boost the learners' minds and help the learners in understanding the phenomenon in question in a better way would be welcomed.

Learning English plays a crucial role in today's progressive societies. With the huge advancements in the realm of science and technology, one would be in favor of synchronizing with these nascent approaches towards life. In doing so, learners of different languages tend to apply catalyzing tools (Christison, 1996), as to simplify this process as much as possible.

\footnotetext{
${ }^{1}$ Corresponding Author
} 
Music, on the other hand, is one of the inseparable parts of humans' lives and applying some musical and rhythmic methods are believed to simplify the process of teaching and have an impact on its output, i.e. learning, which is dealt with in this study. Music, as it is believed, is a common concept of human's life which there is no exact definition for. However, it has been regarded as "conveying the internal or external feelings via sounds" (Torab, 1994, p.3). There are some similarities between this field of art and teaching English. For instance, both enjoy a unique alphabet, both deal with special rhymes and patterns and both interact with the learner's mind and the concept of data processing via getting the data, analyzing that and finally, creating an image which is said to be the output of this complicated process.

Recently, there has been an increasing interest in using musical and rhythmic methods of education in order to improve the learners' skills as subjected to cognitive issues in TEFL (Hille et al., 2011). Musical and rhythmic patterns of teaching may contribute to the act of learning. In this regard, dealing with each and every element included in the act of TEFL can be useful. In this regard, the present study aimed to investigate any statistical relationships involved between music on the one hand and spelling skill of students on the other. In other words, the impact using rhythmic methods exerted on the act of spelling was the man aim of this study. The present work tended to answer the following questions:

1. Is there any statistically significant relationship among using rhythmic methods and the skill of spelling English words as an individual output?

2. Is the gender of the learners dealing with methods of rhythmic and nonrhythmic spelling of English vocabularies involved as an effective factor in the spelling output?

\section{Literature Review}

The deep relationship among music and language would support their discriminate use to improve the output of language acquisition. As Stansell (2005, p.3) points out, this relationship has been previously "described in the earliest cultural records, enacted throughout the development of infants, evidenced from cognitive scientists and utilized by innovative teachers and therapists". Recognition of melodies and notes, rhythm, tonality, prediction and perception of the sight, sound and form of symbols in context are essential segments of both music and language. Like 
"supportive sisters, they comprise separate, though complimentary systems of structured communication,... Language primarily responsible for content and music evoking emotion" (Jourdain, 2009, p.24).

The search for the relationship between music and language, which are both within the initial tools invented by humans, has been progressively reported. According to Stansell (2005), music can affect the language accent, memory and grammar of individual learners in a positive way. In addition, the mood, enjoyment and motivation of the learners could be included as well. Stansell (2005) also argues that language teachers and music therapists should encourage the study of these two similar areas, as communicating through a musical medium would be considered as a beneficial teaching-related activity to everyone.

An empirical perspective would relate to the effect of using musical and rhythmic methods while spelling a word or a combination of words. A study conducted by Chiles (2006) aimed at determining the impact of using music on spelling skills of second grade students. The study was carried out with special reference to the spelling of the words with high frequencies of usage. In doing so, the teacher composed some songs based on familiar tunes to introduce and review twelve words. In addition, other twelve words were introduced and reviewed without a song. Two of the targeted high-frequency spelling words were introduced at one time, one word with a song and one word without a song. A similar timing was spent to introduce and review both words for seven days. Students were then tested bi-weekly on the two current high-frequency spelling words and results were recorded. Students were tested again on all twenty-four targeted spelling words. Findings of the study revealed that music would positively affect second grade students' accuracy.

Playing a musical instrument seems to have a great deal of contribution to the act of learning English itself. In another study conducted by Hille et al. (2011), a group of 194 males in third grade were studied through measuring their reading and spelling performance on the one hand, and their non-verbal intelligence on the other. Their parents were primarily asked about their musical activities since preschool. The results revealed that intelligence was higher for males playing an instrument $(p<.001)$. In order to minimize the role of any interfering factor, Hille et.al (2011) excluded families with no instrumental background. The effect on intelligence remained $(p<.05)$. The results also revealed that the males playing an instrument performed generally better in spelling, as compared with the males who 
were not playing, despite family members with instruments $(p<.01)$. This effect was observed independently of IQ. The study finally suggested an association between music education and general cognitive ability, as well as a specific language link.

The scope of using music seems to be vaster than just spelling. Using information from the National Center for Educational Statistics, Morrison (1994) reported that on a sample size of 13327 high school sophomores, those who participated in music reported higher grades in English, math, history, and science than those who did not participate in music. Therefore, there was a positive correlation between music and the afore-mentioned fields of science.

\section{Method}

\subsection{Participants}

108 children learners of English (54 males and 54 females) aged between eight to ten years old participated in this study. In fact, the participants were from six different levels (three males and three females classes), each consisting of 18 students. These students were chosen among those studying English at The Iran Language Institute, Children's Department, through purposive sampling. The educational program deployed in the department suggests four stages for students, namely Primer (1 and 2), Step Up (1 to 4), Move Up (1 to 4) and Jump Up (1 to 4). In choosing the participants of the study, six classes were selected including Primer 2 (henceforth level 1), Step Up 1 (henceforth level 2) and Step Up 2 (henceforth level 3). The underlying reason for choosing such students in the so-called levels is that the students in other higher levels are not asked to spell out the vocabularies taught previously. In fact, they are just asked to read the words out loud and make sentences with the given words. These sentences could be in an affirmative, a negative or a question form, especially when focusing on different tenses which have been taught recently.

\subsection{Materials}

Two publications, namely An English Primer student book (Iran Language Institute, 2009) and Up \& Away in English 1 student book (Crowther, 1997) were used as the materials of the study. The first publication was compiled and edited by 
The Research and Planning Department of Iran language Institute, Tehran, Iran. Each level deals with teaching around one-hundred new vocabularies during the semester.

\subsection{Data Collection Procedures}

In order to minimize the role of interfering elements involved in the final results of the study, the cross-sectional type was selected to be carried out. To begin with, the students of the three aforementioned levels were instructed how to spell the new vocabularies in both rhythmic and non-rhythmic methods. This included all the vocabularies taught during the three-month period of their education. In other words, if students were taught the new words only with one of the aforementioned methods in discussion, one would strongly argue that it could be an interfering element having a negative impact on the final outcome of the research.

The students were then asked to enunciate the words that had been previously taught at the beginning time of each and every session as their review task. To end with, they were given a test consisting fifty questions with the aim of testing their output in the final session of which ten questions were the spelling ones. In this regard, each student was given ten words to be spelled, five of which had already been taught using the rhythmic method and five with the non-rhythmic one. Appendix 1.provides the carefully recorded marks achieved by each and every student while spelling the words during the final exam.

\section{Findings and Discussion}

In order to provide a general overview on the findings of the study, Table 1. demonstrates the total number of students dealing with the two factors involved in the final output, namely a) using rhythmic vs. non-rhythmic methods and b) gender of the students.

Table 1. Total Number of the Students Dealing with the Two Factors Involved

\begin{tabular}{c|ccc} 
Factor & Code & Value Label & N \\
\hline Gender & 1 & Males & 54 \\
& 2 & Females & 54 \\
Rhythm & 1 & Rhythmic & 54 \\
& 2 & Non-rhythmic & 54
\end{tabular}


In addition, Table 2. provides the readers with the descriptive statistical information derived from the results such as mean, Standard deviation and the frequency of the number of students at each level:

Table 2. Descriptive Statistics of Data

\begin{tabular}{ccccc} 
Gender & Method & Mean & Std. Deviation & N \\
\hline \multirow{2}{*}{ Males } & Rhythmic & 3.6111 & .56302 & 54 \\
& Non-rhythmic & 2.0000 & .41223 & 54 \\
& Total & 2.8056 & .95077 & 108 \\
\multirow{2}{*}{ Females } & Rhythmic & 4.3889 & .50163 & 54 \\
& Non-rhythmic & 2.3519 & .88171 & 54 \\
& Total & 3.3704 & 1.25174 & 108 \\
& Rhythmic & 4.0000 & .65707 & 108 \\
& Non-rhythmic & 2.1759 & .70141 & 108 \\
& Total & 3.0880 & 1.13969 & 216
\end{tabular}

Finally, Table 3.demonstrates the results of the F test.

Table 3. Tests of Between-Subjects Effects

\begin{tabular}{cccccc} 
Source & $\begin{array}{c}\text { Type III Sum } \\
\text { of Squares }\end{array}$ & df & Mean Square & F & Sig. \\
\hline Corrected Model & $66.449^{\mathrm{a}}$ & 3 & 22.150 & 58.443 & .000 \\
Intercept & 686.557 & 1 & 686.557 & $1.812 \mathrm{E} 3$ & .000 \\
Gender & 5.742 & 1 & 5.742 & 15.151 & .000 \\
Rhythm & 59.890 & 1 & 59.890 & 158.025 & .000 \\
Gender * Rhythm & .816 & 1 & .816 & 2.154 & .147 \\
Error & 25.772 & 68 & .379 & & \\
Total & 778.778 & 72 & & & \\
Corrected Total & 92.221 & 71 & & &
\end{tabular}

a. R Squared $=.721$ (Adjusted R Squared $=.708)$

The first column of Table 3.includes the two factors in question along with their interacting effect on one another. The second to sixth columns show the impact level of the two factors in question and their interacting effect in terms of their Sum of Squares Error (SSE), Degree of Freedom (df), Mean of Squares Error (MSE), F and significance level (sig.) respectively. As the significance levels of gender and 
the use of rhythmic methods were less than 0.05 , the tests were then statistically significant and therefore, it could be concluded that these two factors can individually affect the marks achieved by the students in the three aforementioned levels. In other words, there is a significant difference between the marks achieved by male students, as compared with the females. Based on the means presented in Table 2., one would claim that the females have the potentials of achieving much higher marks in this regards (as 3.3704> 2.8056).

As it for the rhythmic vs. non-rhythmic methods, it is important to note that there is a statistically significant difference among the marks achieved in these two methods of teaching. Based on the findings of the study, the rhythmic method ended up with much higher marks (4.0000> 2.1759). However, based on the significance level relating to the binary effect of the factors (0.147>0.05), one would conclude that these two factors could not have a significant effect on each other at the same time. In other words, the effect of the students' gender on the marks achieved at different educational levels are statistically the same and therefore not significant. This fact is illustrated in the following figure:

Findings of the study supported the fact as to how useful utilizing rhythmic methods of teaching could be in an EFL context. The present study focused on the spelling skill of Iranian EFL learners aged between eight and ten years old. The findings also supported the results of the empirical investigation carried out by Hille et.al (2011), in which the significant role of having musical background on the output of learning English was highlighted. Hille et.al (2011) previously found out that playing a musical instrument could significantly boost the spelling skills of EFL learners.

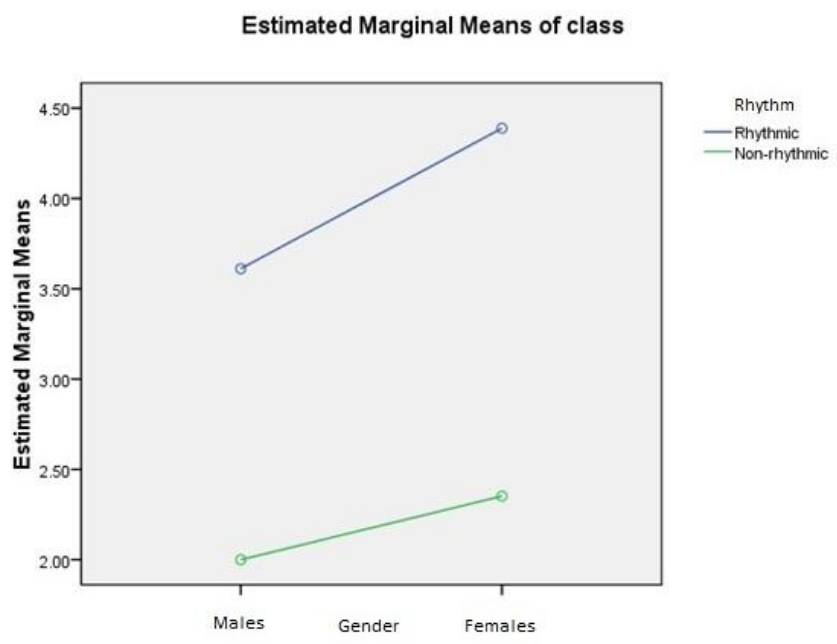

Findings of the present study were also similar to

Figure 1. The Difference Among Males and Females in Using Rhythmic And Non-Rhythmic Methods 
those obtained by Morrison (1994) in terms of the probable impact of music on academic fields of science. According to Morrison (1994), on a sample size of 13327 high school sophomores, those who participated in music reported higher marks in English, as well as other fields of science such as mathematics, history and science. The group of participants who did not achieve high marks were among those who had not any participation in music at all. Similarly, the present study revealed a statistically significant and positive correlation among the use of rhythmic methods on the one hand, and academic achievement (i.e., spelling skill) on the other.

\section{Conclusion}

As it was mentioned before (c.f. the Introduction section), the search for any catalyzing tool has been a worldwide topic of discussion in the realm of TEFL for a long time. In this regard, English instructors and the authorities in the research and planning departments have always been looking for the ways with the aim of simplifying the processes of teaching and learning (Brown, 2000).

Based on the findings of the present study, the female group of learners achieved higher marks in their final examinations with special reference to spelling skill. Therefore, it could be concluded that female learners of English as a second language would react in a better way when they are taught the spellings of the vocabularies in a rhythmic way. This is not to say that male participants may not find the rhythmic method useful; quite the contrary, the rhythmic method was found to be useful for both male as well as female participants of the study. However, its utilization was observed to be more significant in the female group of EFL learners.

The findings of the present study revealed a statistically significant difference among utilizing a rhythmic method to teach the students how to spell out new words, as compared with a non-rhythmic method. In addition, teaching vocabularies to EFL learners with the age limit of eight to ten seems to be a difficult task. Therefore, it could be concluded that the rhythmic method seems to be a more appropriate way of dealing with students in terms of vocabulary teaching and spelling skill. 
Finally, in line with the aforementioned discussions compared to the results of other empirical studies, the instructors and those in charge of educational affairs such as curriculum designers are recommended to use the rhythmic method of teaching English vocabularies. This could in turn help the teachers as well as the students in order to have a better and faster way of teaching and learning such words.

\section{References and notes:}

Brown. H. D. (2000). Principles of language learning and teaching. London: Prentice Hall Inc.

Chiles, R. (2006). The impact of music on the retention of high-frequency spelling words. Shawnee Mission School District. Retrieved December 27, 2012, from http://www.smsd.org

Christison, M.A. (1996). Teaching and learning languages through multiple intelligences. TESOL Journal, 6(1), 10-14.

Crowther, T. G. (1997). Up and away in English. New York: Oxford University Press.

Hille, K., Gust, K., Bitz, U., \& Kammer, T. (2011). Associations between music education, intelligence, and spelling ability in elementary school. Advnces in Cognitive Psychology, 7, 1-6.

Jourdain, R. (2009). Music, the Brain, and Ecstasy: How Music Captures our Imagination. William Morrow and Company, New York.

Katan, D. (2004). Translating cultures: An introduction for translators, interpreters, and mediators (2nd ed.). Manchester: St. Jerome Pub..

Morrison, S. J. (1994). Music students and academic growth. Music Educators Journal,81(2), 33-36.

Stansell, J. W. (2005). The use of music for learning languages: A review OF THE LITTERATURE., MSTE, University of Illinois. Retrieved December 13, 2012, from http://mste.illinois.edu

The Iran Language Institute. (2009). An English Primer. Tehran: Institute for the Intellectual Development of Children and Young Adults Press.

Torab, M. K. (2011). The theory of music: theoretical principles in music. Tehran: Cheshme. 


\title{
Summary
}

\section{The Impact of Rhythm and Gender on Spelling Output of Iranian EFL Learners: A Cross-Sectional Study}

\author{
Peyman Nouraey \\ Gulf College, Muscat, Oman \\ Amin Karimnia \\ Islamic Azad University, Fasa Branch, Iran
}

The present study aimed at investigating the probable effects of gender and rhythmic methods on the final output of Iranian English as a Foreign Language (henceforth EFL) learners with special reference to their spelling skills. In this regard, 108 Iranian EFL learners studying at three different levels were divided into two groups of genders, each consisting of 54 students. Primarily, the students were taught the new English vocabularies using both rhythmic and non-rhythmic methods of spelling. After the trainings, participants were given a test consisting ten marks of spelling in search for the effect of a) gender of the learners and $b$ ) the application of the methods in question. The results of the Two-Way ANOVA test revealed statistically significant gender-derived differences while dealing with spelling. In addition, the results pointed out that both groups of learners achieved much higher marks on the words taught using rhythmic method of spelling rather than the nonrhythmic one.

Key Words: Spelling skill, rhythmic method, non-rhythmic method, TEFL, gender 
The Impact of Rhythm and Gender on Spelling Output of Iranian EFL Learners: ...

Appendix 1. The Spelling Marks Obtained by Iranian EFL Participants

\begin{tabular}{|c|c|c|c|c|c|c|c|c|c|c|c|c|}
\hline \multirow{3}{*}{\begin{tabular}{|c|}
$\begin{array}{c}\text { Gende } \\
\text { r }\end{array}$ \\
Level \\
हe \\
ᄅe
\end{tabular}} & \multicolumn{6}{|c|}{ Males } & \multicolumn{6}{|c|}{ Females } \\
\hline & \multicolumn{2}{|c|}{ Level 1} & \multicolumn{2}{|c|}{ Level 2} & \multicolumn{2}{|c|}{ Level 3} & \multicolumn{2}{|c|}{ Level 1} & \multicolumn{2}{|c|}{ Level 2} & \multicolumn{2}{|c|}{ Level 3} \\
\hline & 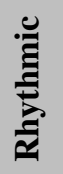 & Z竞 & 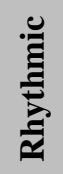 & Ż & 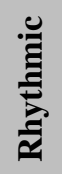 & Z゙ & 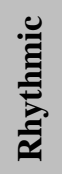 & Z总总 & 总 & Z莫 & 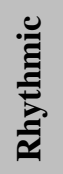 & 总 \\
\hline $\begin{array}{c}\text { Partici- } \\
\text { pant } \\
\text { Code } \\
\end{array}$ & \multicolumn{12}{|c|}{ Marks Obtained $(\operatorname{Max}=5)$} \\
\hline 1 & 5 & 1 & 3 & 1 & 3 & 1 & 5 & 2 & 5 & 1 & 5 & 1 \\
\hline 2 & 5 & 2 & 4 & 1 & 4 & 3 & 5 & 2 & 5 & 1 & 5 & 2 \\
\hline 3 & 3 & 1 & 3 & 2 & 4 & 2 & 4 & 3 & 5 & 1 & 5 & 1 \\
\hline 4 & 4 & 2 & 2 & 2 & 4 & 1 & 5 & 2 & 4 & 1 & 4 & 1 \\
\hline 5 & 2 & 2 & 3 & 1 & 4 & 3 & 5 & 4 & 5 & 2 & 2 & 3 \\
\hline 6 & 4 & 2 & 4 & 2 & 3 & 2 & 5 & 1 & 5 & 4 & 3 & 3 \\
\hline 7 & 3 & 2 & 5 & 1 & 4 & 4 & 4 & 2 & 5 & 2 & 5 & 3 \\
\hline 8 & 3 & 2 & 4 & 3 & 5 & 1 & 3 & 4 & 3 & 3 & 5 & 4 \\
\hline 9 & 4 & 3 & 5 & 1 & 3 & 5 & 5 & 3 & 2 & 2 & 4 & 2 \\
\hline 10 & 3 & 1 & 5 & 5 & 3 & 1 & 5 & 3 & 5 & 1 & 5 & 5 \\
\hline 11 & 4 & 4 & 5 & 1 & 4 & 2 & 4 & 3 & 4 & 4 & 5 & 2 \\
\hline 12 & 3 & 1 & 4 & 1 & 4 & 3 & 4 & 4 & 5 & 5 & 5 & 2 \\
\hline 13 & 2 & 1 & 2 & 2 & 2 & 2 & 2 & 5 & 4 & 4 & 5 & 3 \\
\hline 14 & 3 & 2 & 4 & 2 & 5 & 2 & 4 & 1 & 3 & 3 & 5 & 1 \\
\hline 15 & 4 & 3 & 4 & 2 & 4 & 1 & 5 & 2 & 5 & 1 & 4 & 1 \\
\hline 16 & 3 & 2 & 5 & 3 & 2 & 2 & 3 & 1 & 4 & 1 & 4 & 2 \\
\hline 17 & 4 & 2 & 5 & 3 & 2 & 1 & 4 & 2 & 5 & 2 & 5 & 3 \\
\hline 18 & 3 & 2 & 4 & 1 & 2 & 3 & 5 & 2 & 5 & 2 & 5 & 2 \\
\hline
\end{tabular}

(Highest Mark for Each Row= 5) 